\title{
Yeni Nesil, Modüler ve Akıllı Batarya Yönetim Sistemi
}

\author{
Teoman Karadağ ${ }^{1 *}$, İsmail Can Dikmen ${ }^{2}$ \\ 1* İnönü Üniversitesi, Elektrik-Elektronik Mühendisliği Bölümü, Malatya, Türkiye (ORCID: 0000-0002-7682-7771), teoman.karadag@inonu.edu.tr \\ ${ }^{2}$ İnönü Üniversitesi, Malatya OSB MYO, Elektrik ve Enerji Bölümü, Malatya, Türkiye (ORCID: 0000-0002-7747-7777), can.dikmen@inonu.edu.tr
}

(Uluslararası Araştırma-Geliştirme ve Tasarım Konferansı - 15-18 Aralık 2021)

(DOI: 10.31590 /ejosat.1045564)

ATIF/REFERENCE: Karadag, T. \& Dikmen, IC. (2021). Yeni Nesil, Modüler ve Akıllı Batarya Yönetim Sistemi. Avrupa Bilim ve Teknoloji Dergisi, (32), 1103-1112.

\section{Öz}

Günümüzde başta elektrikli (kara, hava ve deniz) araçlar olmak üzere batarya yönetim sistemleri (BYS), güneş ve rüzgâr gibi yenilenebilir enerji santrallerinin enerji depolama ve yedekliliğinde kritik bir rol oynamaktadır. Bu kapsamda hali hazırda perakende enerji sektöründe bulunan batarya yönetim sistemlerinin tüm fornsiyonlarını yerine getirirken; bu donanımlara bir benzeri dahi olmayan ek inovatif çözümler sunacak yeni nesil, modüler ve akıllı batarya yönetim sisteminin yerli olarak üretilip geliştirilmesi için 2018 yılında TUBİTAK 1512 Teknogirişim Sermaye Desteği Programı kapsamında, 2170454 numaralı ve "E-CAMELEON - Elektrikli Araçlar İçin Adaptif Batarya Yönetim Sistemi” başlılı projesi ile çalışmalara başlanılmıştır. Bu kapsamda BMS'nin ilk versiyonu geliştirilerek, proje başarı ile sonuçlandırılmıştır. Mevcut BSM’nin daha da geliştirilerek farklı çözümler için de kullanılabilmesi adına İnönü Üniversitesi tarafından desteklenen, FOA-2018-1358 numaralı ve "Elektrikli Araçlarda Yeni Nesil Batarya ve Güç Yönetim Sistemlerinin Modellenmesi Geliştirilmesi ve Bataryaların Geri Dönüşüm Süreçlerinin Analizi” başlıklı proje başarı ile tamamlanarak; yerli yazılım, tasarım ve donanım ile yeni nesil, modüler ve akıllı batarya yönetim sistemi geliştirilmiştir. Bu çalışmalar kapsamında "Lityum Tabanlı Piller için Pil Kimyasını Elektronik Olarak Belirleme Yöntemi, 2021/005464, H01M 10/0525”, “Hibrit ve Elektrikli Araç Batarya Ekspertiz Sistemi ve Yöntemi 2021/018933, 2021-GE-827584" ve "Pil Kimyasını Otomatik Belirleyebilen Adaptif, Modüler ve Akıllı Batarya Yönetim Sistemi, 2021/018973, 2021-GE-831229” içeriklerinde üç farklı patent geliştirlmiştir. Tüm bu süreç içerisinde elde edilen sonuçlar çalışmayla sunulmuştur.

Anahtar Kelimeler: Batarya Yönetim Sistemi, Piller, Hibrit ve Elektrikli Araçlar, Enerji Depolama Sistemleri, Geri Dönüşüm.

\section{Next Generation, Modular and Smart Battery Management System}

\begin{abstract}
Today, battery management systems (BMS) play a critical role not only in electric (land, air and sea) vehicles but also electrical energy storage and redundancy of renewable energy plants such as solar and wind. In this regard, for the domestic development and production of a new generation, modular and smart battery management system that fulfills all the functions of BMSs, which are currently in the retail energy sector, and offers additional unique innovative solutions; studies were started in 2018 within the scope of TUBITAK 1512 Entrepreneurship Support Program. The project is numbered 2170454 and titled "E-CAMELEON - Adaptive Battery Management System for Electric Vehicles". As a result of the project, the first version of the BMS with unique features was developed and the project was completed successfully. In order for BMS to be further developed and capable of being used for various solutions; a new project supported by Inonu University has been initiated. The project numbered FOA-2018-1358 and titled "Modelling, Development of New Generation Battery and Power Management Systems in Electric Vehicles and Analysis of the Recycling Processes of Batteries". This proceeding project has also been successfully completed. As the final product of the project, software and hardware were developed with distinctive design, and thus a new generation, modular and smart battery management system was produced. Following these studies three different patent applications completed as "Automatically Determining Battery Chemistry, Adaptive, Modular and Intelligent Battery Management System, 2021/018973, 2021-GE-831229”, "Method for Electronically Determining Battery Chemistry for Lithium-Based Batteries, 2021/005464, H01M 10/0525" and "Hybrid and Electric Vehicle Battery Expertise System and Method 2021/018933, 2021-GE-827584". Now they are in patent pending status. The results obtained from these studies are presented in this paper.
\end{abstract}

Keywords: Battery Management System, Batteries, Hybrid and Electric Vehicles, Energy Storage Systems, Recycling.

\footnotetext{
*Sorumlu Yazar: teoman.karadag@inonu.edu.tr
} 


\section{Giriş}

Elektrik enerjisinin depolanabilmesi ve gerektiğinde depolanan bu enerjinin kullanılması geçmişi uzun yıllara dayanan bir teknik problemdir. $\mathrm{Bu}$ problemin çzümünde en yaygın kullanılan yöntem elektrik enerjisinin kimyasal olarak bataryalara depo edilmesidir. Zaman içerisinde gelişen batarya teknolojisine paralel olarak batarya hücrelerinin yönetim ihtiyacı da ortaya çıkmaya başlamıştır. İlk yeniden şarj edilebilen bataryadan bu yana en yaygın kullanılan batarya kurşun asit bataryalardır. Yapılan akademik ve deneysel çalışmalarla bu bataryaların başta otomotiv sektörü olmak üzere farklı ticari uygulamalarda kullanılabilmesi için verimliliklerinin arttırılması gerekliliği ortaya çıkmıştır. $\mathrm{Bu}$ nedenle kurşun asit bataryaların verimliliklerine etki eden parametrelerin ayrı bir donanım yardımıyla gözlemlenerek kontrol edilmesi gerektiği fikri 1960’lı yıllarda ortaya atılmıştır (Kruger \& Barrick, 1966). Yapılan çalışmalarda, kurşun asit bataryaların verimliliklerine etki eden parametreler akım, gerilim, sıcaklık, şarj durumu, elektrolit yoğunluğu ve hücre yaşı olarak tespit edilmiştir (Kruger \& Barrick, 1966). Böylece bir batarya yönetim sisteminin sahip olması gereken fonksiyonlar genel hatlarıyla ortaya çıkmaya başlamıştır.

Monolitik silikon tümleşik devre teknolojisi 1950'lerde geliştirilmiş ve ilk patent 1959 yılında alınmıştır (Noyce, 1959). Tümleşik devrelerden ve özelleşmiş algılayıcılardan yararlanılarak bataryaların dinamik karakteristikleri tespit edilmekte ve bu karakteristikler yönetim parametrelerinin bazılarının hesaplanması için kullanılmaktadır. $\mathrm{Bu}$ karakteristikleri tanımlamak üzere 1970'li yıllarda çalışmalar başlamıştır (Taylor \& Siwek, 1973). 1980 yılına gelindiğinde daha yüksek performansa sahip, bakımı daha kolay yapılabilen ve enerji depolama kapasitesi kurşun asit bataryalara göre daha yüksek yeni bir batarya teknolojisi geliştirilene kadar kurşun asit bataryalar standart olarak görülmekteydi (Hayden, 1981).

Nikel ve lityum tabanlı batarya teknolojilerinin olgunlaşması ve pazarda yer bulmaya başlamasıyla birlikte 1990'l1 yıllarda taşınabilir cihazlarda kullanılan, pil hücresinin değerlerini okuyarak basit ikazlar verebilen, pil hücresinin gerilimini belirli bir çalışma zarfında tutabilen özelleşmiş tümleşik devreler geliştirilmiştir (Caruthers, 1994; Cates \& Richey, 1996; Freeman, 1995; Goodenough, 1993, 1996b, 1996a; Jones, 1991; Kerridge, 1993; Maliniak, 1995; Swager, 1995). Batarya hücrelerinin kontrollü ve verimli kullanılmasının önem arz ettiği, yüksek güç gerektiren uygulamaların başında elektrikli araçlar gelmektedir. 1996 yılında piyasaya çıkan General Motors EV1 seri üretimi yapılan ilk tam elektrikli araçtır (Glover \& Kimberley, 1996; Johnson, 1999; "Wired Wheels," 1996). EV1 arac1 ile kullanılan Valve-Regulated Lead Acid (VRLA) aküleri yani bakımsız veya kapalı akü olarak bilinen akülerle yapılan saha çalışmalarından elde edilen veriler, bataryaların verimli bir şekilde kullanılabilmesi için aynı zamanda batarya yönetim sisteminin termal kontrol yapması gerekliliğini ortaya koymuştur (Brost, 1998). Bu bağlamda 90’lı yılların sonunda bir batarya yönetim sisteminin sahip olması gereken temel fonksiyonlar şunlardı (Jossen et al., 1999; Masaak et al., 1998).

- Veri toplama

- Batarya durumunun belirlenmesi (Şarj durumu)

- Elektrik yönetimi

- Termal yönetim

- Güvenlik yönetimi

\section{- İletişim}

Veri toplama fonksiyonu, hem batarya hem de aracın güç verilerinin algılayıcılar yardımıyla ölçülmesini ve kayıt edilmesini ifade etmektedir. Çünkü batarya yönetim sisteminin tüm algoritmaları giriş bilgisi olarak ölçülen ve/veya hesaplanan verileri kullanmaktadır. Burada doğruluk ve örnekleme oranı uygulama türüne bağlı olarak değişmektedir fakat her durumda sistemin işleyişi bakımından hayati öneme sahiptir. Örneğin, elektrikli araç uygulamalarının örnekleme oranları saniyede 1 örnekten $(1 \mathrm{~Hz})$ daha hızlıyken, elektrikli uçak uygulamalarında örnekleme oranları saniyede 50 örnekten $(50 \mathrm{~Hz})$ fazladır (Jossen et al., 1999; Zhang et al., 2018). Bu fonksiyon ile batarya giriş/çıkış akımı, baratarya ve ayrı ayrı hücre gerilimleri, batarya sıcaklığı, ortam sıcaklığı vb. değerler ölçülmektedir.

Batarya durumunun saptanması işlevi, bataryanın çeşitli durumlarını ifade eden şarj durumu (State of Charge-SoC), sağlık durumu (State of Health - SoH), enerji durumu (State of EnergySoE) ve kalan faydalı ömür (Remaining Useful Life - RUL) gibi çeşitli parametrelerin belirlenmesini anlatmaktadır. Bataryanın durumunun saptanması, hem kullanıcılar hem de sistem için önem arz eden parametrelerdir. Bununla beraber; batarya yönetim sistemi dâhilindeki elektrik yönetimi için bir giriş değeri olarak değerlendirilmektedir. SoC, SoH, SoE ve RUL değerlerinin hesaplanmasi; veri toplama fonksiyonuna ek olarak araç ve batarya paketi beraberinde mevcut olan algilayıcılardan temin edilen veriler ile sağlanmaktadır.

Bataryanın çalışması esnasında elektriksel ve fiziksel limitlerini aşılmaması güvenlik yönetim fonksiyonun görevidir. Bunun için gereken en temel işlevler deşarj derinliğinin takip edilmesi ve derin deşarja karşı bataryanın korunabilmesidir. Bütün bunlara ilaveten aşırı akım, gerilim ve sıcaklık durumlarında da bu fonksiyon görevini tam olarak yerine getirebilmelidir. Yaşanabilecek olası bir çarpışma ve/veya elektrolit gaz sızıntısı halinde bataryayı acil durum kontaktörleri aracılığı ile sistemden otomatik bir şekilde ayırıp gerekli müdahaleyi zamanında yapabilmelidir.

İletişim fonksiyonu, batarya yönetim sisteminin bağlı tüm bataryaların donanımlarıyla ve araç üzeri haberleşme sistemi ile doğrudan haberleşebilmesidir. Bunun sağlanabilmesi için de, güncel olarak yaygın şekilde batarya donanımları arasında I2C, SPI gibi protokoller kullanılmaktayken; araç ile haberleşme amaciyla standartlaşmış olan CAN-BUS protokolü kullanılmaktadır. (ISO 11898 Road Vehicles — Controller Area Network (CAN), n.d.; Richards, 2002).

Raylı sistemler alanında elektrikli trenler yaygın kullanılan bir teknoloji olmasına rağmen batarya gücü ile çalışan raylı sistemler oksijen gerektirmediği ve gaz salınımı yapmadıkları için genellikle madenlerde kullanılmaktadır. $\mathrm{Bu}$ bataryalı elektrikli araçlara örnek olarak halatlı kepçeler, yük taşıma kamyonları, çekici kamyonlar, matkaplar, servis araçları, birincil kırıcılar, kepçeler, ayna sondaj makinesi, küçük kamyonlar, lokomotifler, kaya bulonlama teçhizatı, konveyörler verilebilir. Bunların dışında bataryalı patlayıcı yükleyiciler ve bataryalı LED 1 şık kuleleri madenlerde kullanılmaktadır (Ertugrul et al., 2020). Madenlerde çalışmak üzere tasarlanmış elektrikli raylı araçlara özel batarya yönetim sistemleri de geliştirilmiştir (Huang et al., 2021).

Elektrikli hafif raylı araçlar konusunda enerji depolama sistemi sadece süperkapasitörlerden teşkil edilmiş raylı sistem araçları konusunda hücre dengelemesi üzerine çalışma 
yapılmıştır. $\mathrm{Bu}$ çalışmada geliştirilmiş bir itme-çekme dönüştürücüsünden türetilen ve yüksek akım kapasitesine sahip voltaj dengeleme devresi ile hücre dengeleme süresini kısaltmak ve hücre dengeleme verimliliğini artırmak için tahmin edilen hücre davranışlarına dayalı bir voltaj dengeleme algoritması önerilmiştir (L. Li et al., 2017).

Hibrit enerji depolama sistemleri konusunda, süperkapasitör, yakıt hücresi ve batarya kombinasyonları ile çalışan enerji depolama sistemleri için enerji yönetimi üzerine çalışmalar yapılmıştır. $\mathrm{Bu}$ çalışmalarda enerji verimliliğini arttırmak ve dolayısıyla işletme maliyetlerini düşürmek için optimal enerji depolama sistemi boyutu ve enerji yönetim algoritmaları sunulmuştur (Cheng et al., 2018, 2017; Da Moraes et al., 2019; Gao et al., 2019; V. Herrera et al., 2016; V. I. Herrera et al., 2016; Kang et al., 2020; Krastevm et al., 2015; Peng et al., 2020; Sarma \& Ganguly, 2020).

Elektrikli deniz araçlarını küçük ölçekli elektrikli botlardan uluslararası taşıma yapan elektrikli gemilere kadar farklı ölçeklerde incelemek mümkündür. Bu konuda yapılan derleme çalışmaları genel olarak sıfır emisyonlu sürdürülebilir taşımacılık, bununla bağlantılı olarak limanların elektrikli gemilere uygun hale getirilmesi ve bunun şebekeye etkileri başlıkları altında incelenmiştir (Anwar et al., 2020; Fang et al., 2020; Groppi et al., 2021; Jeong et al., 2020; Kumar \& Zare, 2019; Ma et al., 2021; Mutarraf et al., 2018; Nguyen et al., 2020; Nuchturee et al., 2020; Pfeifer et al., 2020).

Zaman içerisinde batarya yönetim sistemi fonksiyonlarında kullanılan yöntemler de gelişmektedir. 2021 yılına gelindiğinde BMS'ler batarya paketi içerisinde yer alan paralel bağlı hücrelerden bir tanesinin arızalı olup olmadığını anlayacak kadar gelişmiş yapay sinir ağlarına sahip olmuştur (Lumertz et al., 2021). Dengeleme konusunda batarya geliştirilen yöntemler batarya dinlenme halindeyken, aktif durumdayken ve çalışırken batarya hücreleri arasındaki denge farkını azaltma çalışmaları yapılmıştır (Ziegler et al., 2021). Şarj ve sağlık durumunu daha doğru tahmin etmek için gelişmiş şarj durumu ve sağlık durumu kestirim algoritmaları üretilmiştir (Singirikonda \& Obulesu, 2021). Günümüzün en önemli teknolojilerinden birisi olan büyük veri de batarya yönetim sistemlerine dâhil edilmiştir (S. Li \& Zhao, 2021).

Kısacası BYS, bataryaları veya batarya paketlerini Şekil 1' de gösterildiği gibi, önceden tanımlanmış bir akım, gerilim ve sıcaklık zarfı içinde çalışmasını sağlayan kritik öneme sahip, vazgeçilmez sistemlerdir. Bunu yaparken de en temel iki çıktısı Şarj Durumu ve Sağlık Durumudur. Şarj durumu aracın menzil gibi yan çıktıları üretmesi için önem arz ederken; sağlık durumu ise batarya grubunun toplam enerji depolama kapasitesi ile doğrudan ilişkilidir. BYS'ler mobil cihazlar gibi küçük hatta mikro ölçekli uygulamalarda kullanılabildiği gibi; şehir şebekelerini besleyen çok büyük boyutlu uygulamalarda da, yenilenebilir enerji santrallerinin enerji yedekliliğinde de kullanılabilmektedir.

$\mathrm{Bu}$ çalışmada, yerli ve milli olarak yazılım ve donanım tasarımları tamamen bize ait, mevcut BYS'lerin sahip olduğu fonksiyonları yerine getirirken, alanında bir ilk olan iki özgün ve yeni fonksiyona sahip yeni nesil, akıllı batarya yönetim sistemi detaylarıyla sunulmuştur.

Eklenen tanılama algoritması ile BMS'ye bağlanan bataryanın kimyası elektronik olarak tespit edilmektedir (İsmail Can Dikmen et al., 2018). Sağlık durumu algoritması ile de yeni bir yöntem kullanılarak bataryanın sağlık durumu tespit edilebilmektedir.

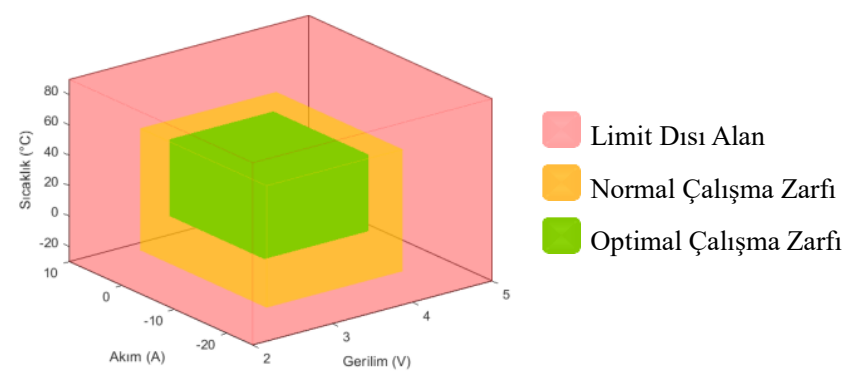

Şekil 1 Örnek Li-ion pil optimal çalışma zarfi.

\section{Materyal ve Metot}

Bir batarya yönetim sisteminin sahip olması gereken tüm temel fonksiyonlar ve bunlara ek olarak tarafımızca geliştirilmiş olan yeni fonksiyon özellikleri için batarya yönetim sistemi donanımında iki farklı kart tasarımı ALTIUM yazılımı kullanılarak yapılmıştır. Bunlardan ilki ana kart ikincisi ise yardimcı karttır.

\subsection{Elektronik DC Yük}

Deneysel çalışmada programlanabilir DC yük kullanılmıştır. $\mathrm{Bu}$ cihaz LABview yazılımı ile programlanarak; bataryaların değişken yükler karşısındaki kararlılık durum analizleri test edilmiştir. Kullanılan cihaz Şekil 2'de gösterilen Prodigit 3350F modeli olup 1200 watt gücüne sahiptir. Maksimum 120 A ve $60 \mathrm{~V}$ desteklemektedir.

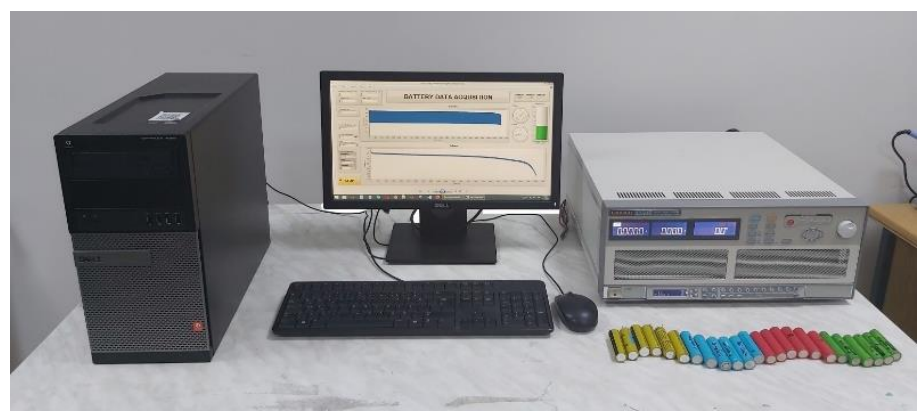

Şekil 2 Elektronik DC Yük ve kontrol yazılımı.

\subsection{Raspberry Pi ve Dokunmatik Ekran}

Geliştirilen batarya yönetim sisteminin ara yüzü, Python programlama dilinde yazılmıştır. Ayrıca high side fonksiyonlarının (SoC vb.) hesaplanması ve BMS algoritmasının koşturulması için Cortex M4 işlemcili Raspberry Pi 3 geliştirme kartı kullanılmıştır. Bu kart sayesinde sistemden çekilen veriler, grafiğe dönüştürülerek ara yüz doğrudan dokunmatik ekranına aktarılarak görselleştirilmiştir. Böylece BYS üzerindeki tüm veriler, grafiksel görsellere dönüştürülerek etkileşimli olarak kullanıcılar için sunulmuştur. 

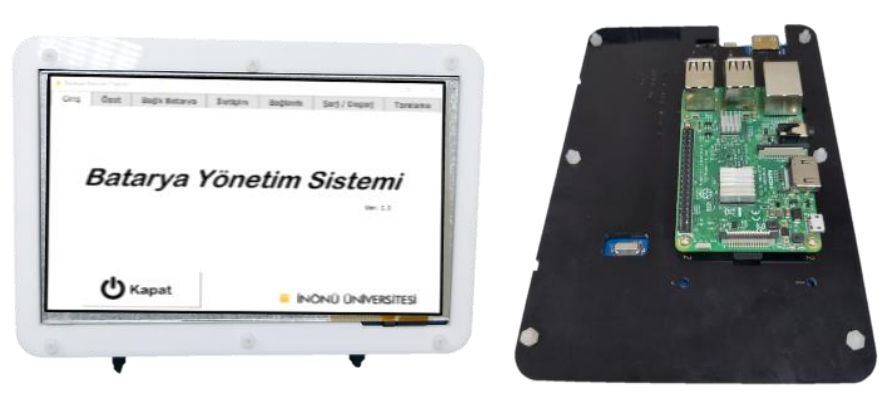

Şekil 3 Raspberry PI ve Donunmaik Ekran

\section{Araştırma Sonuçları ve Tartışma}

\subsection{Donanım}

\subsubsection{BYS Ana Kart}

BYS ana kart tasarımında ise dört adet bataryayı ayrı ayrı yüke veya şarja bağlayabilecek ve bunu yaparken de hem akım sınırlaması hem de gerilim kontrolü yapabilecek bir tasarım yapılmıştır. Anahtarlama elemanı olarak ilk tasarımda MOSFET'ler kullanılmıştır. MOSFET'lerin güvenli çalışması, kısa devreye sebep olmaması için bir çoğullayıcı(mux) devreye dâhil edilmiştir.

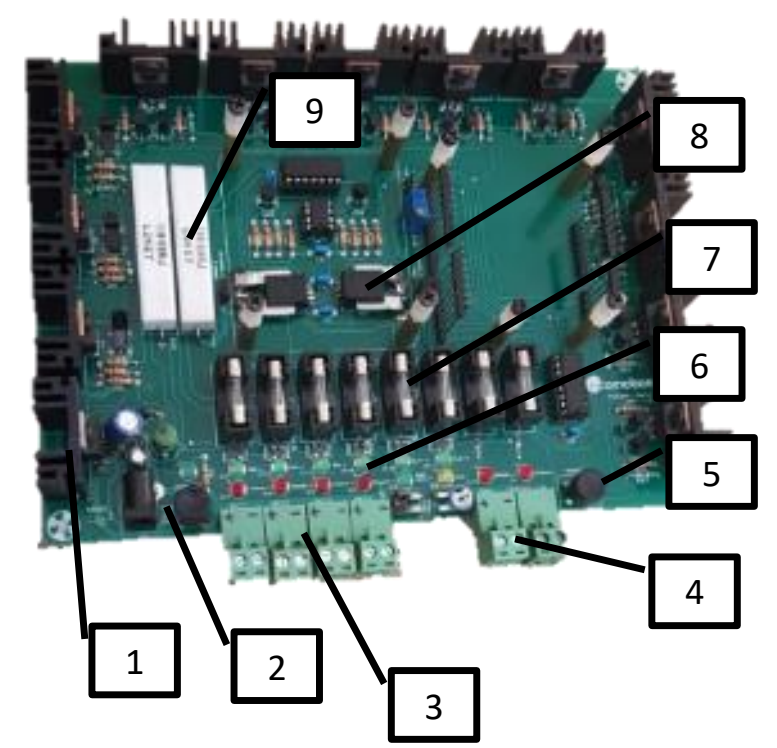

Şekil 4 Ana Kart Ver. 1.0

Şekil 4'de ana kartın birinci tasarımı sunulmuştur. Burada, 1 nolu devre elemanı batarya paketlerinin anahtarlaması için kullanılan MOSFET'lerdir. 2 ile gösterilen giriş beslemesi soketi ve açma kapama düğmesidir. 3 ile gösterilen soketler dört farklı kimyaya sahip batarya paketlerinin ana karta bağlandığı girişleri, 4 nolu soketler ise ana karta bağlı bataryanın şarj veya deşarj için ayrı ayrı çıkış noktasını ifade etmektedir. Ana kartın 5 numaralı kısmı RESET düğmesidir. 6 ile gösterilen LEDler hangi bataryanın şarja/deşarja veya tanılama yüklerine bağlı olduğunu ayrı ayrı ifade etmektedir. 7 ile gösterilen devre elemanları cam tüp tipi 8 amperlik sigortalardır. 8 ile gösterilen hall effect akım sensörleri ve 9 ile gösterilen devre elemanları ise tanılama yük dirençleridir.

BYS ana kartının üzerinde üretim sonrası yapılan testlerde anahtarlama noktasında kartta görülen eksiklik ve aksaklıkların giderilmesi amacıyla sistem bir bütün olarak ele alınarak güncellenmiş ve kart tasarımı geliştirilerek BYS ana kartının ikinci versiyonu tasarlanarak üretilmiştir. Ana kartın ikinci versiyonunda anahtarlama elemanı olarak röleler kullanılmış ve ilk versiyona ek olarak iki donanımsal ve bir yazılımsal olmak üzere üç katmanlı akım koruması sisteme eklenmiştir.

Şekil 5'de sunulan ana kartta rölelerin güvenli bir şekilde sürülebilmesi için kullanılan çoğullayıcı(mux) reset düğmesi 1 ile gösterilmiştir. 2 ile gösterilen POT(ayarlı direnç) donanımsal akım korumasının kesim değerini ayarlamak için kullanılmaktadır. 3 ile dört farklı kimyaya sahip batarya paketlerinin anakarta bağlandığı giriş soketleri gösterilmiştir. 4 ile akım sensörü gösterilmiştir. 5 ile bağlı bataryanın şarj veya deşarj için ayrı ayrı çıkış bağlantı soketleri gösterilmiştir. 6 ile gösterilen devre elemanları tanılama yük dirençleridir. 7 ile gösterilen devre elemanları donanımsal akım korumasının ikinci basamağı olan cam tüp tipi 8 amperlik sigortalardır. 8 ile gösterilen devre elemanları anahtarlama röleleridir. 9 ile gösterilen giriş beslemesi soketi ve açma kapatma düğmesidir.

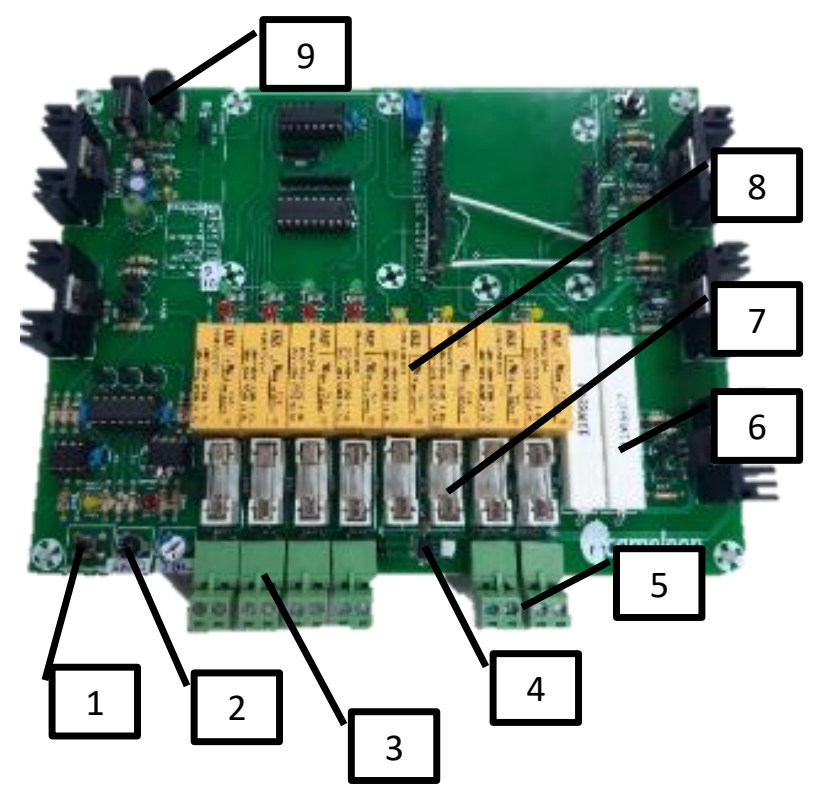

Şekil 5 Ana Kart Ver. 2.0

CAN haberleşmesi için altyapı sağlaması ve yazılım geliştirme kolaylıkları bakımından ana kart kontrolünde Atmega328 mikro kontrolör seçilmiştir. Tüm bunların yanında ana kart üzerinde bağlanan bataryaların tipinin tanılanması ve gelecekte kullanılabilecek farklı batarya tiplerinin tanılanması için bir devre yer almaktadır (İ C Dikmen \& Karadağ, 2021; İsmail Can Dikmen \& Karadağ, 2021).

\subsubsection{BYS Yardımcı Kartı}

Yardımcı kart tasarımlarında 18 adet hücre ile oluşturulacak bir batarya paketi esas alınarak tasarım yapılmıştır. $\mathrm{Bu} 18$ hücrenin gerilimlerini ayrı ayrı okuyabilen ve böylece batarya paketini yönetebilen bir sistem tasarlanmıştır. Bunun için öncelikle ALTIUM programı ile PCB tasarımı yapılarak ilk versiyonu üretilmiştir. İlk versiyon ile yapılan testler sonucunda görülen eksiklik ve aksaklıklar sebebiyle tasarım güncellenerek nihai versiyonu üretilmiştir. Yardımcı kartın ilk versiyonunu Şekil 6'da sunulmuştur.

Şekil 7'de ise nihai versiyon yer almaktadır. Yardımcı kartlar master kart ile izole edilmiş SPI bağlantısı üzerinden haberleşmektedirler. 


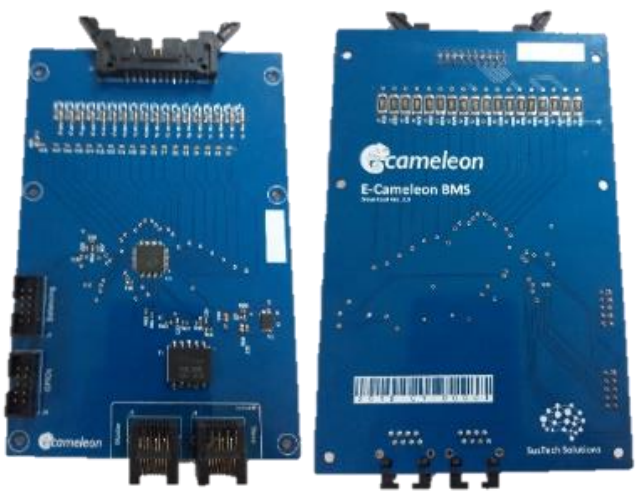

Şekil 6 Yardımcı Kart Ver 1.0

$\mathrm{Bu}$ sayede galvanic izolasyon sağlanmaktadır. Bu özellik otomotiv sanayiinde kullanılan batarya yönetim sistemleri için çok gerekli bir özelliktir.
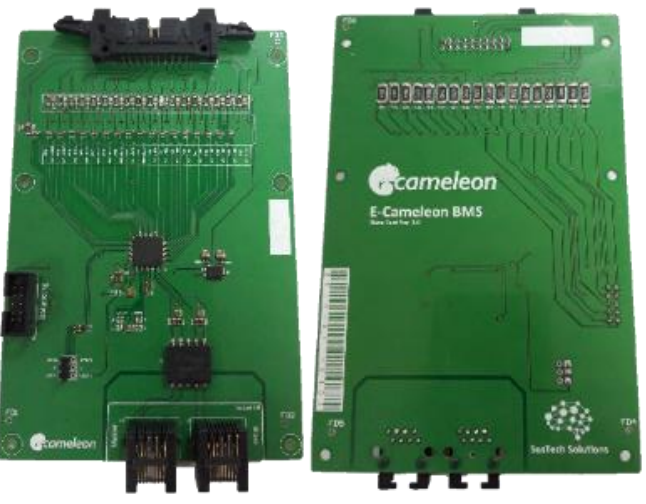

Şekil 7 Yardımcı Kart Ver 1.0

\subsection{Yazılım}

Ana/yardımcı kart kontrolü için $\mathrm{C}++$ tabanlı, özgün bir yazılım geliştirilmiştir. $\mathrm{Bu}$ yazılım ile temel olarak iki işlev öngörülmüştür. Bunlardan ilki yardımcı kartlardan alınan verilerin işlenmesi ve ana karta gönderilmesidir. İkinci işlevi ise ana kartın kontrolüdür. Yazılımın birinci işlevi için izoleli SPI bağlantı ile yardımcı kartlardan alınan veriler bütünleştirilerek derlenip ara yüz yazılımına USB bağlantısı üzerinden gönderilmektedir. $\mathrm{Bu}$ sayede ara yüz üzerinde BYS verileri detaylarıyla gösterilebilmektedir. İkinci işlevi olan ana kart kontrolü için ise yine yazılımsal olarak güvenli (karşılıklı teyitli) bir şekilde ana kart üzerindeki rölelerin ve/veya MOSSFET'lerin sürülmesi gerçekleştirilmektedir. Tüm bu işlemler, ara yüz yazılımı tarafından USB bağlantısı üzerinden gönderilen komutların uygulanması ve teyit/hata mesajının geri gönderilmesi şeklinde yapılandırılmıştır. Bu sayede ara yüz yazılımı gönderdiği her komut için teyit alarak işlem yapmaktadır. Tüm bunlara ek olarak sisteme bağlı bataryaların şarj durumlarını(SoC) ölçümlemek/kestirmek için iki yöntem tercih edilmiştir. Bunlardan ilki ve daha doğru sonuç verdiği tespit edilen yöntem cloumb sayma metodudur. İkinci yöntem ise bataryaların yaşlandırma verilerinden elde ettiğimiz veri seti kullanılarak uygulanan kestirim metodudur.

Python programlama dilinde, mini bilgisayar (Raspberry pi 3) üzerinde çalışan bir ara yüz yazılımı geliştirilmiştir. Bu yazılım BYS tarafından elde edilen verilerin ve ana kart kontrolünün kullanıcı dostu bir şekilde görselleştirilmesinin yanı sıra arka planda batarya kimyası tanılama, SoC ve SoH kestirimi gibi işlemsel maliyeti yüksek algoritmaların uygulanması işlevini görmektedir. Bu da bir dokunmatik LCD ekran üzerinde verilerin görselleştirilmesini sağlamaktadır.

$\mathrm{Bu}$ ara yüzde kullanıcı dostu, yedi farklı sayfa bulunmaktadır. Bu sayfalardan ilki "Giriş" sayfasıdır. Temel olarak dokunmatik ekran ile kullanın bu yazılımın sonlandırılması ve kullanıcı karşılama işlevini görmektedir. (Video)

İkinci sayfa ise "Özet" sayfasıdır. Bu sayfada bağlı bulunan batarya grubunun hangisi olduğu en altta gösterilmektedir. Bağlı bulunan batarya grubunun hangi kimyaya sahip olduğu ve buna göre datasheet verileri, paket değerleri bölümünde gösterilmektedir. Anlık BMS değerleri kısmında ise bağlı bulunan batarya paketinin şarj durumu (SoC), anlık olarak batarya akımının şarj veya deşarj olma durumuna göre ayrı ayrı gösterilmektedir. Ayrıca bataryanın anlık gücü, sıcaklığı ve batarya içerisinde yer alan hücrelerden en düşük ve en yükssek gerilime sahip olanların gerilim değerleri tek tek gösterilebilmektedir.

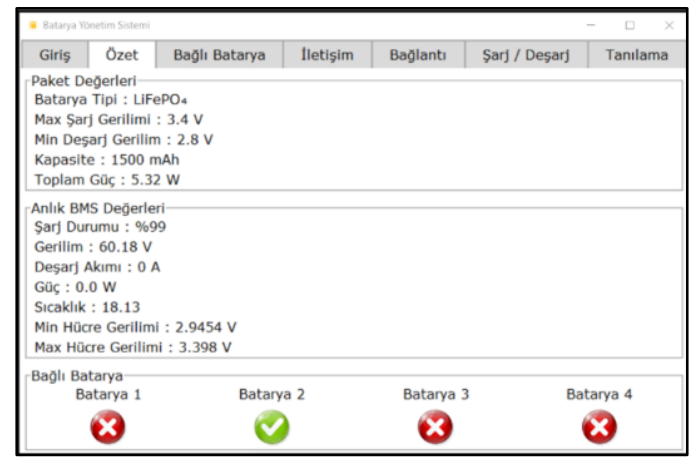

Şekil 8 Arayüz Özet sayfası

Üçüncü sayfa "Bağlı Batarya" sayfasıdır. Bu sayfada bağlı bulunan bataryanın içerisinde yer alan hücrelerin teker teker gerilimleri noktadan sonra dördüncü basamak hassasiyetinde sunulmaktadır. Ayrıca parametreler kısmında bataryanın toplam gerilimi, şarj veya deşarj olma durumuna göre akımı, gücü, sıcaklığı, şarj durumu (SoC) ve batarya kimyası gösterilmektedir. Burada kullanılan renklendirme pilin kimyasına göre değişmektedir. Bu çalışmada Li-ion piller için kırmızı, LiFePO4 piller için mavi, Ni-Mh piller için yeşil ve Ni-Cd piller için de beyaz renk kullanılmıştır.

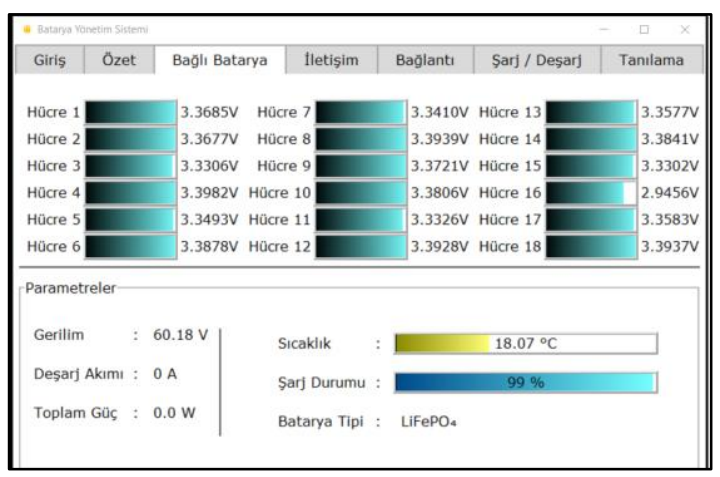

Şekil 9 Arayüz Bağlı Batarya sayfası

Dördüncü sayfa "İletişim" sayfasıdır. Bu sayfada bilgisayar veya Rasberry Pi'nin hangi iletişim portu üzerinden BYS ile iletişim kuracağı seçilebilmektedir. Yazılım bunu otomatik olarak yapmasına rağmen tüm seçenekleri açılır bir menüde sunmaktadır. Bağlantı kurulması durumunda yazı ile hangi port üzerinden bağlantı kurulduğunu göstermektedir. USB kablosunun çıkarılıp tekrar takılması gibi durumlarda bağlantının yeniden 
sağlanabilmesi için, hazır olan bağlantı port adreslerinin güncellenmesi gerekmektedir.

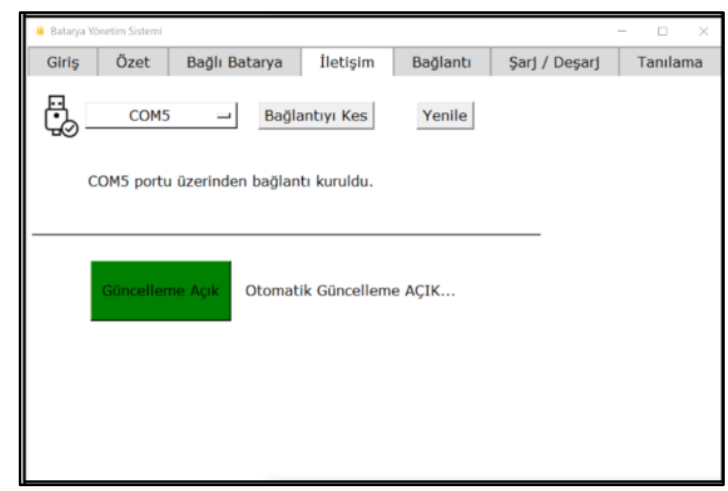

Şekil 10 Arayüz İletişim sayfası

Bu işlem için "Yenile" butonu bulunmaktadır. Sayfa altında yer alan "Otomatik Güncelleme" fonksiyonu $2 \mathrm{~Hz}$. Tazeleme hızı ile (yarım saniyede bir) BYS sisteminden gelen verilerin arayüz ekranında gösterilmesini sağlamaktadır. Yazılımda bu fonksiyon tamamen otomatik olarak çalışmakla birlikte istenildiği takdirde kapatılabilmesi için bir buton yerleştirilmiştir.

Beşinci sayfa "Bağlantı" sayfasıdır. Bu sayfada hangi batarya grubunun fiziksel olarak bağlanacağı seçilebilmekte ve bağlantı görsel olarak sunulmaktadır. En alt kısımda bulunan buton ile bataryaların sisteme bağlanmaya hazır olduğu komutu verilmektedir. Aynı zamanda bu buton ile tüm bataryalar sistemden fiziksel olarak ayrılabilmektedir. Batarya 1-4 butonları bataryaların bağlı oldukları kontaktör veya MOSFET'lerin aktivasyonu için kullanılmaktadır. Bu butonların aktive ettiği fonksiyonlar elektriksel bir arızaya sebebiyet vermemek için arka planda diğer tüm bağlantıları teyitli bir şekilde kapatıp sadece ilgili bataryanın sisteme teyitli olarak bağlanmasını sağlamaktadır. Bu tarz bir anahtarlama algoritması ile sistemin çalışma güvenliği sağlanmaktadır. Ayrıca butonlar üzerinde o an bağlı olan bataryanın kimyası da yazmaktadır.

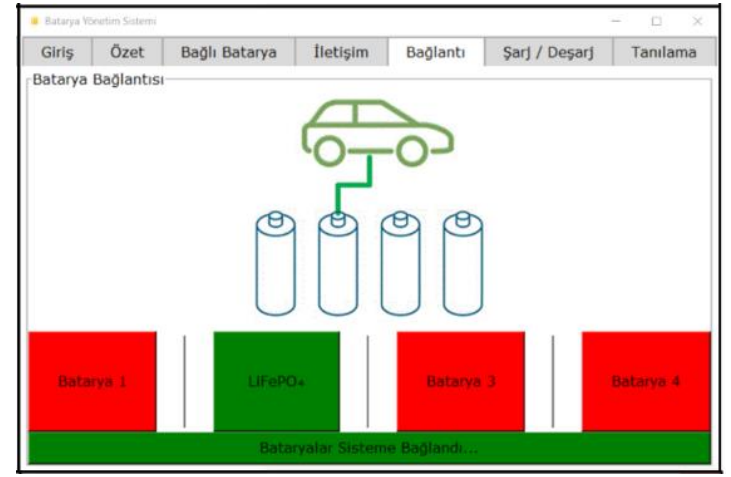

Şekil 11 Arayüz Bağlantı sayfası

Altıncı sayfa "Şarj/Deşarj” sayfasıdır. Bu sayfada tek bir buton yer almaktadır. Varsayılan olarak deşarj durumundadır. $\mathrm{Bu}$ da sistemin bataryalardan yüke bağlı olduğu anlamına gelmektedir. Bağlı bataryanın şarj edilebilmesi için uygun anahtarlamanın yapılabilmesi bu buton ile sağlanmaktadır. Diğer fiziksel bağlantı butonları ile aynı güvenli bağlantı algoritması ile çalışmaktadır.

Yedinci sayfa "Tanılama" sayfasıdır. Bu sayfada yer alan tanılama butonuna basıldığında tanılama algoritması koşturularak bağlı olan bataryaların kimyası tespit edilip Tanılama Sonucu bölümünde gösterilmektedir.

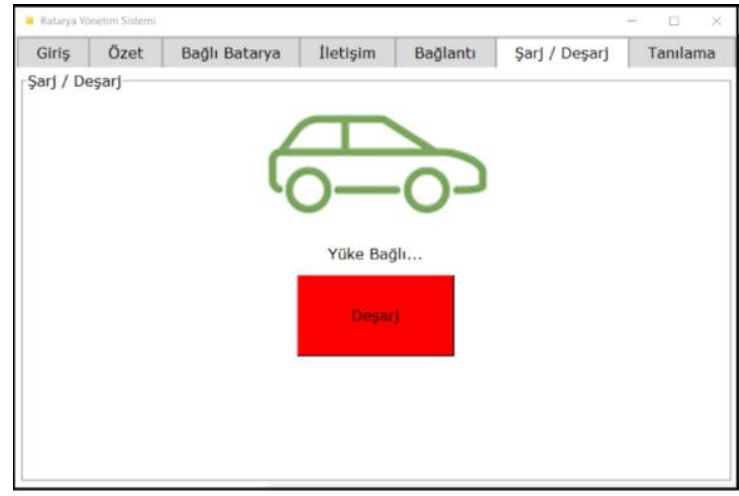

Şekil 12 Arayüz Şarj/Deşarj sayfası

Burada tanılama algoritmasının çalıştı̆̆ batarya grubu sarı renk ile gösterilirken tanılaması tamamlanmış batarya grupları yeşil renk ile gösterilmektedir.

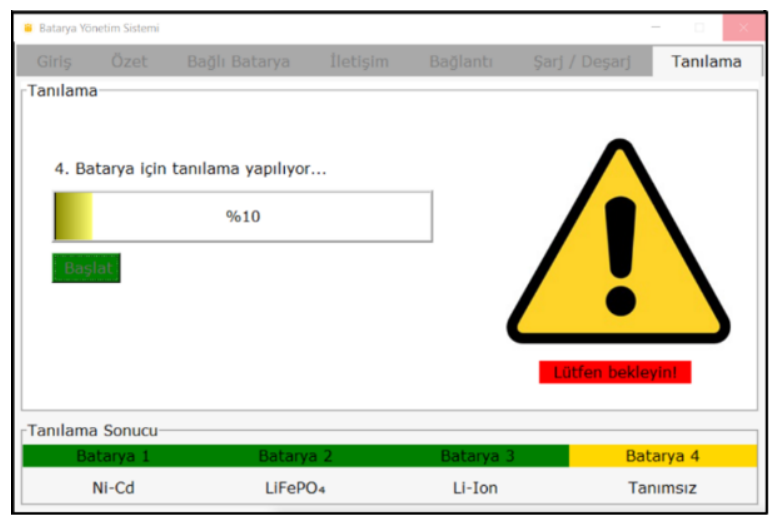

Şekil 13 Arayüz Tanılama sayfası

\subsection{Tanılama Yöntemi}

Batarya yönetim sistemi yazılımı ve donanımı hemen hemen her uygulamada tasarlandığı batarya hücresinin kimyasına bağlıdır. Bunun yanı sıra, batarya yönetim sistemi mimarisi farklı uygulamalara göre büyük ölçüde farklılık gösterir. Bu nedenle, yeniden yapılandırılabilir batarya yönetim sistemi mimarisi veya ikinci ömür uygulamaları gibi bazı özel uygulamalar, otomatik hücre kimyası belirleme özelliğine ihtiyaç duymaktadır. Burada, yeniden yapılandırılabilir mimari farklı batarya türlerinin üstün özelliklerinden yararlanmak için batarya paketleri arasında geçiş yapma yeteneğini ifade eder. İkinci ömür ise özellikle elektrikli araçlar gibi yüksek güç isteyen ve batarya sağlı̆̆ının önem arz ettiği uygulamalarda, bataryalar gerekli performans kriterlerini karşılamadıklarında ilk kullanımından farklı uygulamalarda (örneğin elektrik şebekelerinde) kullanılması anlamına gelir. Her iki uygulama örneğinde de batarya hücresinin kimyasının otomatik olarak belirlenmesi bir mühendislik problemdir. $\mathrm{Bu}$ çalışmanın özgün değerinin başında [Tanılama Referans/Patent]'de detayları verilen batarya kimyasını tespit etme yöntemi gelmektedir. Bunun için yapılmış olan projeler kapsamında gerçekleştirilen deneysel ve matematiksel çalışmalar sonucunda geliştirilmiş özgün yazılım ve donanım ile batarya kimyasını tanılama sistemi BYS'nin ana kart tasarımına dâhil edilmiştir. Böylece elektrikli araç ve enerji depolama sistemlerine yönelik perakende sektöründe olmayan eşsiz bir ürün geliştirilmiştir. (Video)

\subsection{SoH Algoritması}

Çalışmanın bir diğer özgün yönünü ise veri temelli SoH tespit yöntemleri kategorisinde yer alan, çalışma kapsamında 
geliştirilmiş ve patent başvurusu yapılmış olan özgün sağlık durumu tespit algoritması, geliştirilen BYS'de kullanılmıştır. Geliştirilmiş olan bu özgün SoH algoritması, gelişmiş bir sağlık durumu tespiti algoritmasıdır (GSoH). Diğer sağlık durumu tespit algoritmalarından farklı olarak tam şarj ve/veya tam deşarj gerektirmeden kısmı şarj yada deşarj ile batarya sağlık durumunu tespit edebilmektedir.

\subsection{BYS Fonksiyonları}

Zaman içerisinde değişen ihtiyaçlar, gelişen teknoloji ve talepler doğrultusunda batarya yönetim sistemleri de günün ihtiyaçları doğrultusunda evrilmişlerdir. 2011 yılına gelindiğinde bir batarya yönetim sisteminin sahip olması gereken fonksiyonlar şu şekildedir (Xing et al., 2011).

- Veri toplama

- Güvenlik koruması

- Bataryanin durumunu belirleme ve tahmin etme yeteneği

- Şarj ve deşarj kontrolü

- Hücre dengeleme

- Termal yönetim

- Batarya durumunun ve kimlik doğrulamasının yapılıp bir kullanıcı arayüzüne gönderilmesi

- Tüm batarya bileşenleriyle iletişim

- Daha uzun pil ömrü
2021 y1lına gelindiğinde ise batarya yönetim sisteminin sahip olması gereken fonksiyonlar aşağıdaki gibi tanımlanmıştır (Wang et al., 2020):

- Veri toplama

- Modelleme ve durum tahminleri

- Şarj ve deşarj kontrolü

- Arıza teşhisi

- Sağlık yönetimi

- Termal yönetim

- Hücre dengeleme

- İletişim

- IOT teknolojileri ile uyum(Haldar et al., 2020; Sivaraman \& Sharmeela, 2020)

- $\quad$ Bulut teknolojileri (Kim et al., 2018)

Batarya teknolojisinin gelişimi, batarya ile çalışan cihaz çeşitliliğinin artması ve özellikle elektrikli araçlar gibi yüksek güç uygulamalarındaki gereklilikler ışı̆̆ında batarya yönetim sistemlerinin teknolojileri birbirlerine paralel olarak gelişmiştir. Tabloda yıllar içerisinde batarya yönetim fonksiyonlarının gelişimi verilmiştir. Burada dikkat çeken husus temel fonksiyonların kaybolmadan önem ve yerlerini korumalarıdır. Teknolojik gelişime paralel olarak gerekli fonksiyonların zaman içerisinde batarya yönetim sistemlerine entegre edildiği görülmektedir.

Tablo 1. BYS fonksiyonlarının karşılaş̧ırması

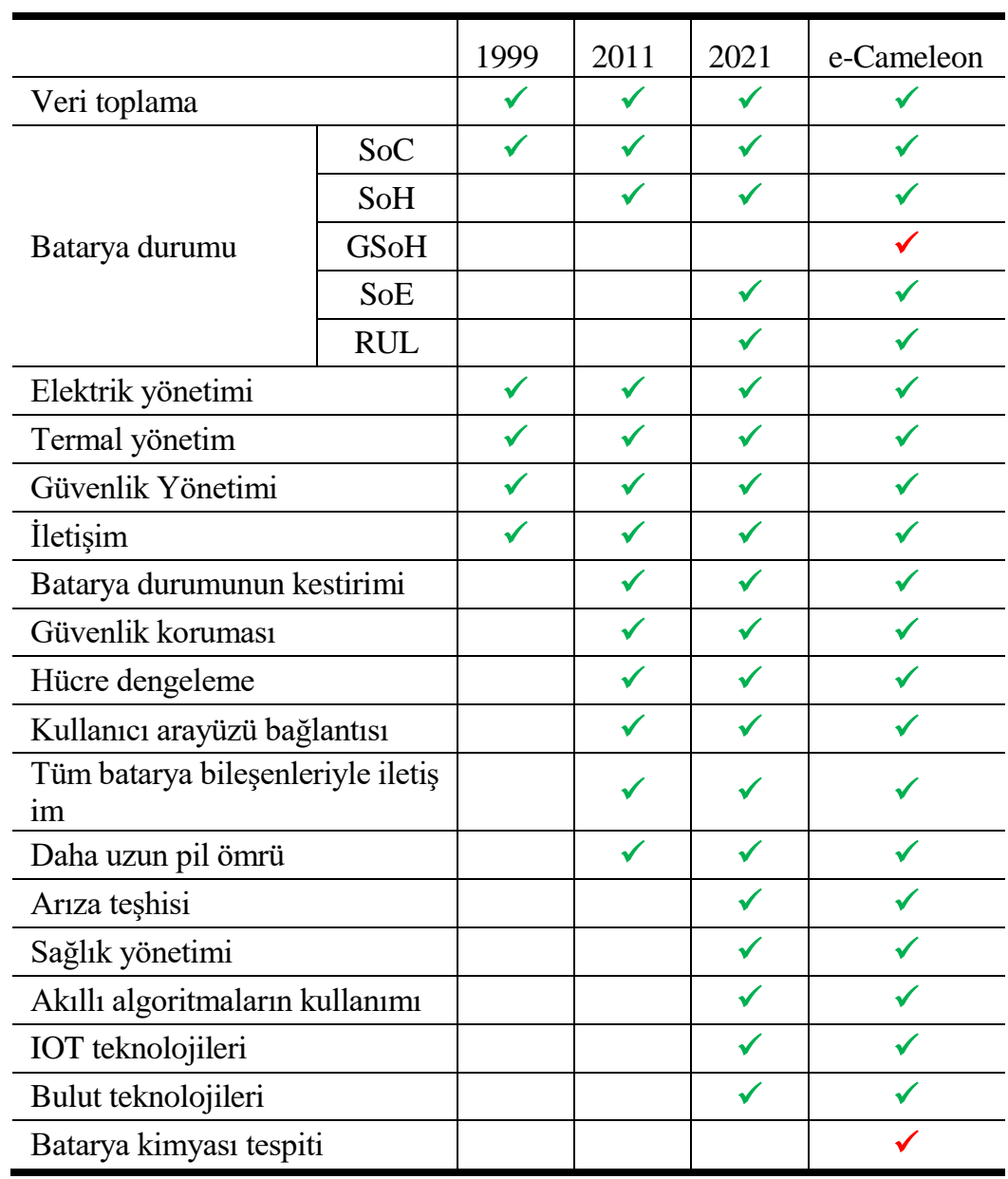




\section{Sonuç}

2016 yllında başlayan bu çalışma bir doktora tezi çalışmasıdır. Bu kapsamda Malatya Teknopark'ında TÜBİTAK 1512 Tekno Girişim Sermaye desteği alınarak ilk defa bu kapsamda bir şirket kurulmuştur. 2018 yılında TUBITAK 1512 Teknogirişim Sermaye Desteği Programı kapsamında, 2170454 numaralı ve "E-CAMELEON - Elektrikli Araçlar İçin Adaptif Batarya Yönetim Sistemi” başlıklı projesi ile çalışmalara başlanılmıştır. Bu kapsamda BMS'nin ilk versiyonu geliştirilerek, proje başarı ile sonuçlandırılmıştır. Çalışmalar, proje dâhilinde devam etmiş ve proje başarı ile tamamlanmıştır. Mevcut BSM'nin daha da geliştirilerek farklı çözümler için de kullanılabilmesi adına İnönü Üniversitesi tarafından desteklenen, FOA-2018-1358 numaralı ve "Elektrikli Araçlarda Yeni Nesil Batarya ve Güç Yönetim Sistemlerinin Modellenmesi Geliştirilmesi ve Bataryaların Geri Dönüşüm Süreçlerinin Analizi” başlıklı proje başarı ile tamamlanarak; yerli yazılım, tasarım ve donanım ile yeni nesil, modüler ve akıllı batarya yönetim sistemi geliştirilmiştir. Bu çalışmalar kapsamında "Lityum Tabanlı Piller için Pil Kimyasını Elektronik Olarak Belirleme Yöntemi, 2021/005464, H01M 10/0525", "Hibrit ve Elektrikli Araç Batarya Ekspertiz Sistemi ve Yöntemi 2021/018933, 2021-GE827584" ve "Pil Kimyasını Otomatik Belirleyebilen Adaptif, Modüler ve Akıllı Batarya Yönetim Sistemi, 2021/018973, 2021GE-831229” içeriklerinde 3 farklı patent geliştirlmiştir.

$\mathrm{Bu}$ kapsamda hali hazırda perakende enerji sektöründe bulunan batarya yönetim sistemlerinin tüm fonksiyonlarını yerine getirirken; bu donanımlara bir benzeri dahi olmayan ek inovatif çözümler sunacak yeni nesil, modüler ve akıllı batarya yönetim sistemi yerli yazılım, tasarım ve donanım ile üretilerek geliştirilmiştir.

Böylece gerek elektrikli araç (hava, kara, deniz) üreticileri ve gerekse yenilenebilir enerji santrallerinde enerjinin depolanmasına yönelik yapılacak tüm çalışmalarda batarya kimyasından bağımsız olarak üretim ve depolama sağlanabilecektir. Geliştirilmiş olan BMS ise çoklu kimyalı batarya kullanımları sayesinde, farklı üstün özelliklere sahip bataryalar birlikte kullanılabilecek ve verim artacaktır.

Cumhurbaşkanlığı Strateji ve Bütçe Başkanlığı'nın hazırlamış olduğu 11. Kalkınma Planının 399. Maddesinde belirtildiği üzere, "Ülkemizde yakın mesafe yolcu ve araç taşımacılığında kullanılan gemilerin çevre ve enerji dostu tam elektrikli gemilere dönüştürülmesine yönelik program başlatılacak ve benzer uygulamaların yaygınlaştırılması desteklenecektir." benzer olarak fosil yakıtlı araçların (hava, kara, deniz) tam elektrikli araçlara dönüşü ve elektrikli araçların ömrünü tamamlayan batarya paketlerinin değişiminde batarya kimyasına bakılmaksızın, kullanıcı ihtiyaçlarına yönelik batarya tercihi ve araç üzerinde kullanımı sağlanabilecektir.

Yeni nesil, modüler ve akıllı batarya yönetim sistemi, çevresel faktörler de göz önüne alınarak ayrı ayrı patentlerini geliştirmiş olduğumuz batarya kimyasını tanılama ve batarya sağlık durumunun tespiti $(\mathrm{SoH})$ yöntemleri sayesinde ömrünü tamamlamış pillerin kimyalarına göre ayrıştırılması ve ikincil hayata kazandirılacak pillerin hem kimyasına hem de kalan ömrüne göre ayrıştırılarak sınıflandırılması amacıyla kullanılabilecek inovatif bir Ar-Ge çalışmasıdır.
Projeler:

$>$ E-CAMELEON - Elektrikli Araçlar İçin Adaptif Batarya Yönetim Sistemi TÜBİTAK 1512 Teknogirişim Sermaye Desteği Programı Proje No: 2170454

> Elektrikli Araçlarda Yeni Nesil Batarya ve Güç Yönetim Sistemlerinin Modellenmesi Geliştirilmesi ve Bataryaların Geri Dönüşüm Süreçlerinin Analizi İnönü Üniversitesi Bilimsel Proje No: FOA-20181358

\section{Patentler:}

$\checkmark \quad$ "Lityum Tabanlı Piller için Pil Kimyasını Elektronik Olarak Belirleme Yöntemi, 2021/005464, H01M 10/0525"

$\checkmark \quad$ "Hibrit ve Elektrikli Araç Batarya Ekspertiz Sistemi ve Yöntemi 2021/018933, 2021-GE-827584"

$\checkmark$ "Pil Kimyasını Otomatik Belirleyebilen Adaptif, Modüler ve Akıllı Batarya Yönetim Sistemi, 2021/018973, 2021-GE-831229"

\section{Teșekkür}

Bir fikri, uluslararası bir ürün olma yolunda destekleyen TÜBİTAK ve İnönü Üniversitesi Bilimsel Araştırma Projeleri Koordinasyon Birimine teşekkür ederiz.

\section{Kaynakça}

Anwar, S., Zia, M. Y., Rashid, M., Rubens, G. Z., \& Enevoldsen, P. (2020). Towards Ferry Electrification in the Maritime Sector. In Energies (Vol. 13, Issue 24). https://doi.org/10.3390/en13246506

Brost, R. D. (1998). Performance of valve-regulated lead acid batteries in EV1 extended series strings. Proceedings of the Annual Battery Conference on Applications and Advances, 25-29. https://www.scopus.com/inward/record.uri?eid=2s2.0-

$0031675716 \&$ partnerID $=40 \& \mathrm{md} 5=\mathrm{c} 2 \mathrm{f} 407383 \mathrm{f} 57 \mathrm{af} 95 \mathrm{ba} 2 \mathrm{c} 5$ $3 \mathrm{c} 0 \mathrm{de} 88297 \mathrm{f}$

Caruthers, F. (1994). Battery-management Circuitry Gets Smarte. Computer Design's OEM Integration, May, 15-18.

Cates, R., \& Richey, R. (1996). Charge NiCd and NiMH Batteries Properly. Electronic Design, June 10, 118-122.

Cheng, L., Acuna, P., Aguilera, R. P., Jiang, J., Flecther, J., \& Baier, C. (2017). Model predictive control for Energy Management of a hybrid energy storage system in Light Rail Vehicles. 2017 11th IEEE International Conference on Compatibility, Power Electronics and Power Engineering, CPE-POWERENG 2017, https://doi.org/10.1109/CPE.2017.7915255

Cheng, L., Wang, W., Wei, S., Lin, H., \& Jia, Z. (2018). An improved energy management strategy for hybrid energy storage system in light rail vehicles. Energies, 11(2). https://doi.org/10.3390/en11020423

Da Moraes, C. G., Junior, S. L. B., Cavilha, P. P., Pacheco, A. L. S., Heldwein, M. L., \& Waltrich, G. (2019). Multi-Port System for Storage and Management of Regenerative Braking Energy in Diesel-Electric Locomotives. 2019 IEEE 15th Brazilian Power Electronics Conference and 5th IEEE Southern Power Electronics Conference, COBEP/SPEC 
2019.

https://doi.org/10.1109/COBEP/SPEC44138.2019.9065725

Dikmen, İ C, \& Karadağ, T. (2021). Onboard Battery Type Determination. 2021 5th International Symposium on Multidisciplinary Studies and Innovative Technologies (ISMSIT), https://doi.org/10.1109/ISMSIT52890.2021.9604658 $360-365$.

Dikmen, İsmail Can, \& Karadağ, T. (2021). Lityum Tabanlı Piller için Pil Kimyasını Elektronik Olarak Belirleme Yöntemi (Patent No. Patent No:2021-GE-212728). https://portal.turkpatent.gov.tr/anonim/arastirma/patent/sonu c/dosya?patentAppNo=2021\%2F005464\&documentsTpye $=$ all

Dikmen, İsmail Can, Seven, S., \& Karadağ, T. (2018). A Numerical Study for Automatic Battery Identification in Hybrid Battery Packs for Electric Vehicles. Proceedings of the International 9th Automotive Technologies Congress, $825-832$.

Ertugrul, N., Kani, A. P., Davies, M., Sbarbaro, D., \& Morán, L. (2020). Status of Mine Electrification and Future Potentials. 2020 International Conference on Smart Grids and Energy Systems (SGES), 151-156. https://doi.org/10.1109/SGES51519.2020.00034

Fang, S., Wang, Y., Gou, B., \& Xu, Y. (2020). Toward Future Green Maritime Transportation: An Overview of Seaport Microgrids and All-Electric Ships. IEEE Transactions on Vehicular Technology, 69(1), 207-219. https://doi.org/10.1109/TVT.2019.2950538

Freeman, D. (1995). Freeing Portables from Battery Tyranny. Electronic Design, July 10, 115-121.

Gao, F., Zhang, G., Shi, Y., \& Qiang, G. (2019). Energy Management Strategy for New Type Urban Rail Vehicle Hybrid Power System . Tiedao Xuebao/Journal of the China Railway Society, 41(4), 48-54. https://doi.org/10.3969/j.issn.1001-8360.2019.04.007

Glover, M., \& Kimberley, W. (1996). Kind of hush. Automotive Engineer (London), 21(6) https://www.scopus.com/inward/record.uri?eid=2-s2.00030379484\&partnerID $=40 \& \mathrm{md} 5=41 \mathrm{f} 683 \mathrm{ae} 8437770 \mathrm{cff} 764$ 7810c7e9f4f

Goodenough, F. (1993). Battery-based Systems Demand Unique ICs. Electronic Design, 39(14), 47-61.

Goodenough, F. (1996a). Battery Management ICs Meet Diverse Needs. Electronic Design, August 19, 79-96.

Goodenough, F. (1996b). Microcontroller Grabs Data and Processes Analogue Data. Electronic Design, April 15, 139 144.

Groppi, D., Pfeifer, A., Garcia, D. A., Krajačić, G., \& Duić, N. (2021). A review on energy storage and demand side management solutions in smart energy islands. Renewable and Sustainable Energy Reviews, 135, 110183. https://doi.org/https://doi.org/10.1016/j.rser.2020.110183

Haldar, S., Mondal, S., Mondal, A., \& Banerjee, R. (2020). Battery Management System Using State of Charge Estimation: An IOT Based Approach. 2020 National Conference on Emerging Trends on Sustainable Technology and Engineering Applications (NCETSTEA), 1-5. https://doi.org/10.1109/NCETSTEA48365.2020.9119945

Hayden, C. L. (1981). Electric vehicle battery management. SAE Technical Papers. https://doi.org/10.4271/810417

Herrera, V. I., Gaztañaga, H., Milo, A., Saez-De-Ibarra, A., Etxeberria-Otadui, I., \& Nieva, T. (2016). Optimal Energy Management and Sizing of a Battery-Supercapacitor-Based
Light Rail Vehicle with a Multiobjective Approach. IEEE Transactions on Industry Applications, 52(4), 3367-3377. https://doi.org/10.1109/TIA.2016.2555790

Herrera, V., Milo, A., Gaztañaga, H., Etxeberria-Otadui, I., Villarreal, I., \& Camblong, H. (2016). Adaptive energy management strategy and optimal sizing applied on a batterysupercapacitor based tramway. Applied Energy, 169, 831845. https://doi.org/10.1016/j.apenergy.2016.02.079

Huang, K., Wang, Y., \& Feng, J. (2021). Design of lithium-ion battery management system for mine electric vehicle. IOP Conference Series: Earth and Environmental Science, 680(1). https://doi.org/10.1088/1755-1315/680/1/012015

ISO 11898 Road vehicles - Controller area network (CAN). (n.d.). International Organization for Standardization (ISO). https://www.iso.org/standard/63648.html

Jeong, B., Jeon, H., Kim, S., Kim, J., \& Zhou, P. (2020). Evaluation of the Lifecycle Environmental Benefits of Full Battery Powered Ships: Comparative Analysis of Marine Diesel and Electricity. In Journal of Marine Science and Engineering (Vol. 8, Issue 8). https://doi.org/10.3390/jmse8080580

Johnson, B. C. (1999). Environmental products that drive organizational change: General motor's electric vehicle (EV1). Corporate Environmental Strategy, 6(2), 140-150. https://doi.org/https://doi.org/10.1016/S10667938(00)80024-X

Jones, G. (1991). Battery Management in Modem Portable Systems. Electronic Engineering, 43-52.

Jossen, A., Späth, V., Döring, H., \& Garche, J. (1999). Reliable battery operation - a challenge for the battery management system. Journal of Power Sources, 84(2), 283-286. https://doi.org/https://doi.org/10.1016/S03787753(99)00329-8

Kang, J., Guo, Y., \& Liu, J. (2020). Rule-based energy management strategies for a fuel cell-battery hybrid locomotive. 2020 IEEE 4th Conference on Energy Internet and Energy System Integration: Connecting the Grids Towards a Low-Carbon High-Efficiency Energy System, EI2 2020 ,

$45-50$ https://doi.org/10.1109/EI250167.2020.9346652

Kerridge, B. (1993). Battery Management ICs. EDN, May 13, $100-108$.

Kim, T., Makwana, D., Adhikaree, A., Vagdoda, J. S., \& Lee, Y. (2018). Cloud-Based Battery Condition Monitoring and Fault Diagnosis Platform for Large-Scale Lithium-Ion Battery Energy Storage Systems. In Energies (Vol. 11, Issue 1). https://doi.org/10.3390/en11010125

Krastevm, I., Mukherjee, N., Tricoli, P., \& Hillmansen, S. (2015). New modular hybrid energy storage system and its control strategy for a fuel cell locomotive. 2015 17th European Conference on Power Electronics and Applications, EPEECCE $\quad$ Europe 2015. https://doi.org/10.1109/EPE.2015.7309371

Kruger, R., \& Barrick, J. W. (1966). Battery ratings. SAE Technical Papers. https://doi.org/10.4271/660029

Kumar, D., \& Zare, F. (2019). A Comprehensive Review of Maritime Microgrids: System Architectures, Energy Efficiency, Power Quality, and Regulations. IEEE Access, 7, 67249-67277. https://doi.org/10.1109/ACCESS.2019.2917082

Li, L., Huang, Z., Li, H., \& Peng, J. (2017). A rapid cell voltage balancing scheme for supercapacitor based energy storage systems for urban rail vehicles. Electric Power Systems 
Research,

142 ,

https://doi.org/10.1016/j.epsr.2016.09.021

$329-340$.

Li, S., \& Zhao, P. (2021). Big data driven vehicle battery management method: A novel cyber-physical system perspective. Journal of Energy Storage, 33, 102064. https://doi.org/https://doi.org/10.1016/j.est.2020.102064

Lumertz, M. M., da Cruz, F. G., Lamperti, R. D., Pasa, L. A., \& Marujo, D. (2021). Damaged Cell Location on Lithium-Ion Batteries Using Artificial Neural Networks BT - Control Applications in Modern Power System (A. K. Singh \& M. Tripathy (Eds.); pp. 477-486). Springer Singapore.

Ma, S., Lin, M., Lin, T.-E., Lan, T., Liao, X., Maréchal, F., Van herle, J., Yang, Y., Dong, C., \& Wang, L. (2021). Fuel cellbattery hybrid systems for mobility and off-grid applications: A review. Renewable and Sustainable Energy Reviews, 135, 110119. https://doi.org/https://doi.org/10.1016/j.rser.2020.110119

Maliniak, D. (1995). Intelligence Invades the Battery Pack. Electronic Design, January 9, 153-159.

Masaak, S., Kiyoak, K., Masahiko, K., Yoshiaki, T., \& Hiroshige, S. (1998). Electronic Apparatus, Battery Management System, and Battery Management Method (Patent No. 5635813).

Mutarraf, M. U., Terriche, Y., Niazi, K. A., Vasquez, J. C., \& Guerrero, J. M. (2018). Energy Storage Systems for Shipboard Microgrids-A Review. In Energies (Vol. 11, Issue 12). https://doi.org/10.3390/en11123492

Nguyen, H. P., Hoang, A. T., Nizetic, S., Nguyen, X. P., Le, A. T., Luong, C. N., Chu, V. D., \& Pham, V. V. (2020). The electric propulsion system as a green solution for management strategy of $\mathrm{CO} 2$ emission in ocean shipping: A comprehensive review. International Transactions on Electrical Energy Systems, n/a(n/a), e12580. https://doi.org/https://doi.org/10.1002/2050-7038.12580

Noyce, R. N. (1959). Semiconductor device-and-lead structure (Patent No. US2981877A).

Nuchturee, C., Li, T., \& Xia, H. (2020). Energy efficiency of integrated electric propulsion for ships - A review. Renewable and Sustainable Energy Reviews, 134, 110145. https://doi.org/https://doi.org/10.1016/j.rser.2020.110145

Peng, H., Li, J., Löwenstein, L., \& Hameyer, K. (2020). A scalable, causal, adaptive energy management strategy based on optimal control theory for a fuel cell hybrid railway vehicle. Applied Energy, 267. https://doi.org/10.1016/j.apenergy.2020.114987

Pfeifer, A., Prebeg, P., \& Duić, N. (2020). Challenges and opportunities of zero emission shipping in smart islands: A study of zero emission ferry lines. ETransportation, 3, 100048 .

https://doi.org/https://doi.org/10.1016/j.etran.2020.100048

Richards, P. (2002). A CAN Physical Layer Discussion (No. AN228).

http://ww1.microchip.com/downloads/en/appnotes/00228a.p df

Sarma, U., \& Ganguly, S. (2020). Design optimisation for component sizing using multi-objective particle swarm optimisation and control of PEM fuel cellbattery hybrid energy system for locomotive application. IET Electrical Systems in Transportation, 10(1), 52-61. https://doi.org/10.1049/iet-est.2018.5053

Singirikonda, S., \& Obulesu, Y. P. (2021). Advanced SOC and SOH Estimation Methods for EV Batteries-A Review BT Advances in Automation, Signal Processing, Instrumentation, and Control (V. L. N. Komanapalli, N. Sivakumaran, \& S. Hampannavar (Eds.); pp. 1963-1977). Springer Singapore.

Sivaraman, P., \& Sharmeela, C. (2020). IoT-Based Battery Management System for Hybrid Electric Vehicle. In Artificial Intelligent Techniques for Electric and Hybrid Electric Vehicles (pp. 1-16). https://doi.org/https://doi.org/10.1002/9781119682035.ch1

Swager, A. W. (1995). Smart-Battery Technology: Power Management's Missing Link. EDN, March 2, 47-64.

Taylor, D. F., \& Siwek, E. G. (1973). The dynamic characterization of lead-acid batteries for vehicle applications. SAE Technical Papers. https://doi.org/10.4271/730252

Wang, Y., Tian, J., Sun, Z., Wang, L., Xu, R., Li, M., \& Chen, Z. (2020). A comprehensive review of battery modeling and state estimation approaches for advanced battery management systems. Renewable and Sustainable Energy Reviews, 131, 110015. https://doi.org/https://doi.org/10.1016/j.rser.2020.110015

Wired wheels. (1996). Industry Week, 245(20), 50. https://www.scopus.com/inward/record.uri?eid=2-s2.0$8444245678 \&$ partnerID $=40 \& \mathrm{md} 5=\mathrm{b} 72 \mathrm{a} 966737 \mathrm{c} 652 \mathrm{~d} 17 \mathrm{~b} 96$ $1 \mathrm{ab} 2 \mathrm{c} 9 \mathrm{f} 98704$

Xing, Y., Ma, E. W. M., Tsui, K. L., \& Pecht, M. (2011). Battery Management Systems in Electric and Hybrid Vehicles. In Energies (Vol. 4, Issue 11). https://doi.org/10.3390/en4111840

Zhang, X., Liu, L., Dai, Y., \& Lu, T. (2018). Experimental investigation on the online fuzzy energy management of hybrid fuel cell/battery power system for UAVs. International Journal of Hydrogen Energy, 43(21), 10094-10103. https://doi.org/https://doi.org/10.1016/j.ijhydene.2018.04.07 5

Ziegler, A., Oeser, D., Hein, T., Montesinos-Miracle, D., \& Ackva, A. (2021). Reducing cell to cell variation of lithiumion battery packs during operation. IEEE Access. https://doi.org/10.1109/ACCESS.2021.3057125 